\title{
The Effect of Training on Energy Conservation Strategies, Fatigue, and Self-Caring among Women with Breast Cancer Undergoing Chemotherapy in Zahedan Medical Sciences Hospitals in 2018-2019
}

\author{
Fatemeh Sedaghat Khozimeh ${ }^{1}$, Ali Navidian², Pegah Sasanpour ${ }^{3}$, Fatemeh Kiani ${ }^{4}$
}

${ }^{1}$ Department of Nursing, Nursing and midwifery college, Zahedan University of Medical Sciences, Zahedan, Iran. 2Department of Nursing, Community Nursing Research Center, Zahedan University of Medical Sciences, Zahedan, Iran.

${ }^{3}$ Department of Radiotherapy, Zahedan University of Medical Sciences, Zahedan, Iran. ${ }^{4}$ Department of Nursing, Community Nursing Research Center, Zahedan University of Medical Sciences, Zahedan, Iran.

\section{ABSTRACT}

\section{BACKGROUND}

Fatigue is one of the most common cancer-related problems. Fatigue-reduction nondrug methods include energy conservation strategies and improving self-caring efficacy. The aim of the present study was to determine the effect of energy conservation strategies training on fatigue and caring self-efficacy in cancer patients.

\section{METHODS}

It was a single-blind clinical trial study performed on 80 breast cancer patients in educational hospitals in Zahedan (Iran) selected by simple random sampling. After randomly assigning patients to two groups (control and intervention), before the intervention, multidimensional fatigue inventory (MFI) and strategies used by people to promote health (SUPPH) were completed by patients in both groups. The control group received no special care except routine care. The intervention consisted of energy conservation strategies that was performed in the experimental group within 3 individual sessions once a week. Following all 3 training sessions, follow-up was performed for 6 weeks and the questionnaires were then administered to the control and intervention groups and the post-test was given.

\section{RESULTS}

Most of the participants in the two groups were educated less than high school diploma, were housewives, and in stage II of the diseases. The results showed that fatigue was significantly lower in the intervention group than the control group after the intervention $(p=0.01)$. The results also showed a significant improvement in the level of caring self-efficacy in the intervention group compared to the control group $(\mathrm{p}=0.02)$.

\section{CONCLUSIONS}

The results indicate that educational intervention can be used as an effective strategy and a complementary therapy along with other therapies to reduce fatigue in patients with breast cancer.

\section{KEY WORDS}

Fatigue, Breast Cancer, Caring Self-Efficacy

\author{
Corresponding Author: \\ Fatemeh Kiani, \\ Department of Nursing, \\ Community Nursing Research Center, \\ Zahedan University of Medical Sciences, \\ Zahedan, Iran. \\ E-mail: jahant1990@gmail.com
}

DOI: 10.14260/jemds/2019/792

Financial or Other Competing Interests: None.

How to Cite This Article:

Khozimeh FS, Navidian A, Sasanpour P, et al. The effect of training on energy conservation strategies, fatigue, and selfcaring among women with breast cancer undergoing chemotherapy in Zahedan medical sciences hospitals in 2018-2019. J. Evolution Med. Dent. Sci. 2019;8(49): 3661-3666, DOI:
Submission 24-09-2019,

Peer Review 12-11-2019,

Acceptance 18-11-2019,

Published 09-12-2019. 


\section{BACKGROUND}

Breast cancer is the most common cancer in women and the leading cause of cancer-related death in women aged 40 to 44 years. now, breast cancer accounts for 1.3 of all cancers in women and is responsible for $19 \%$ of cancer-related deaths. $(1,2,3)$ Like most developing and developed countries, breast cancer is the most common cancer in Iran and is ranked the first in the country, $(4,5,6,7)$. There are totally 40,000 patients in Iran and more than seven thousand are added to this figure annually. ${ }^{(8)}$

Patients with breast cancer suffer from a variety of physical and psychological complications such as depression, anxiety, pain, and fatigue. One of the most complex and common cancer-related problems is fatigue. Approximately, 72 to $99 \%$ of cancer patients suffer from fatigue.( ${ }^{(9)}$ According to the National Comprehensive Cancer Network (NCCN), cancer-related fatigue is a subjective, unpleasant and persistent symptom that manifests as physical (lack of energy, need to rest), emotional (Reduced motivation or interest), and cognitive fatigue (deficits in concentration and attention).(10,11,12)

Fatigue manifests mainly in a chronic form and is a major complication of cancer treatments, including hormone therapy, and chemotherapy. It disrupts various aspects of the patient's physical, psychological, and social life and, consequently, reducing their quality of life. Despite the high prevalence of cancer-induced fatigue and strategies to alleviate this problem, because attention is not paid to this problem in patients. The main barriers may include false impression of healthcare providers, (because cancer-related fatigue is similar to fatigue experienced by healthy individuals in their daily lives), insufficient knowledge about the basic mechanisms of cancer-related fatigue. They also include a false belief that no action can be taken for this type of fatigue, failure to distinguish this type of fatigue from depression and the inability to understand the negative effects of this complication on quality of life.(13)

Existing studies on psychosocial support, modification of sleep and food habits, and some complementary and alternative therapies, such as massage and touch, yoga, relaxation, meditation, and herbal remedies suggest that these techniques may possibly be useful and effective in reducing or eliminating cancer-related fatigue.(14)

According to a previous study by Tabrizi Moghaddam et al, one of the non-drug fatigue reduction methods and nondrug strategies includes applying energy conservation strategies,(15) to create a balance between rest and activity in the course of the cancer-related fatigue, and understanding the value of rest followed by planning for incorporation of a rest period with self-care programs during the day. $(16,17)$

Considering the high prevalence of fatigue, the educational support needs of women with breast cancer on the one hand, and considering that training on energy conservation strategies and enhancing caring self-efficacy is a non-drug, non-invasive, and low-cost method of controlling physical and psychological problems and can be easily educated to the patient through the nurse, and most of previous studies on cancer patients have emphasized different side effects of chemotherapy and radiotherapy, such as nausea, vomiting, hair loss, other complications, and fatigue, despite all its effects that may have on the cancer patient's life, has been less studied on the other hand, the present study aimed to determine the energy conservation strategies training on fatigue and factors related to caring self-efficacy of cancer patients.

\section{METHODS}

\section{Study Design and Registration}

This Single-blind) clinical trial study was performed on 80 women with breast cancer from January 2018 to May 2019 at two educational hospitals (Ali-ibn Abi Talib and Khatamolanbia hospitals), Zahedan University of Medical Sciences, Iran. This study was registered at the Ethics Committee of Zahedan University of Medical Sciences (Ethic code: IR.ZAUMS.REC.1397.392). This clinical trial was also registered at the Iranian Registry of Clinical Trials (IRCT2017100903665N4). Consort checklist was used to report this study.

Sample size was estimated to be 14 individuals in each group based on fatigue variable in Tabrizi et al.'s study (2016) with 95\% confidence interval and study power $=95 \%$ (18) using. In order to consider possible drop-out and to ensure the adequacy of sample size, 40 individuals were assigned in each group and a total of 80 individuals were included.

\section{Participants}

Participants were patients with breast cancer, who were estimated to be 14 individuals T. Inclusion criteria included individuals aged 20 to 60 years, being at stage I or II, individuals receiving at least one chemotherapy session, being able to communicate and cooperate, lack of cardiopulmonary disease, lack of known psychiatric illness and the use of psychiatric drugs. Exclusion criteria also included being absent in training sessions for one session, failure to implement the training program for 1 week, disease metastasis and patient's death.

\section{Instruments}

Data collection instrument included a three-part questionnaire including demographic characteristics, MFI fatigue questionnaire, and caring self-efficacy questionnaire (SUPPH). Demographic characteristics included (age, marital status, occupation, educational level, treatment strategy, stage of disease, type of surgery, chemotherapy session, and history of disease).

\section{Multidimensional Fatigue Inventory (MFI)}

This instrument helps achieve a deeper understanding of individual's fatigue by assessing five dimensions of fatigue including general fatigue, physical fatigue, reduced activity, reduced motivation, and subjective fatigue.(19) It consists of 20 items rated on a 5-point Likert scale (ranging from $1=$ Yes completely right to $5=$ No, completely wrong). Ultimately higher scores indicate greater fatigue. There are 4 questions for each dimension and Positive and negative have been used simultaneous while writing them down to reduce the likelihood of respondents' bias. (19) This questionnaire was first presented by Smets in 1996 and its validity and reliability were evaluated across different demographic groups, such as cancer patients undergoing radiotherapy, 
patients with chronic fatigue syndrome, first-year psychology and medical students, soldiers, and third-year medical students.(20) This questionnaire has been translated into Persian and its reliability and validity have been confirmed.(21)

\section{Self-Efficacy Questionnaire}

Strategies Used by People to Promote Health (SUPPH)- The self-care self-efficacy questionnaire was first designed by Lev (1997) specifically for cancer patients and translated into Persian and used by Azizi-Fini.(22) The questionnaire consists of 29 questions scored based on 5-point Likert-type ranging from (completely confident $=5$ ) to (poorly confident=1). The questions in this questionnaire investigate an individuals' level of confidence while performing their self-care tasks and the total score is between 29 and 145. This instrument has a self-report state and its internal consistency has been reported 0.94 by calculating Cronbach's alpha.(22)

\section{Procedure}

After coordinating with the person in charge of the oncology department, the researcher explained the goals for patients who met the inclusion criteria. Written consent was obtained from patients who were willing to participate in the study. Initially, participants were selected using convenience sampling and to ensure random allocation of participants, envelopes containing group name cards were first prepared for all study sample studied. The cards were then arranged randomly, with one of these cards being assigned to each of them that determined the individual's group (intervention or control). At the end, the participants of both groups were identified. Before the intervention, the questionnaire was completed by the participants in both intervention and control groups. Questionnaires were completed by the patient with the help of the researcher within 15 minutes. In the intervention group, patients received intervention containing energy conservation strategies in 3 individual sessions once a week. After completing 3 training sessions, follow-up was performed for 6 weeks and the questionnaires were then completed by the participants. The training sessions included a pamphlet and a training booklet, and their scientific content was approved by an oncologist.

\section{Statistical analysis}

At first, frequency, percentage, mean, standard deviation, minimum, and maximum were determined by descriptive statistics. To compare pre and post-intervention means in each group, paired t-test was used. Independent t-test was also used to compare means between intervention and control groups. Covariance Analysis test was used to compare fatigue score between two groups before and after intervention. P-value> 0.05 was considered as the significance level.

\section{RESULTS}

A total of 80 participants were enrolled in the study and were present in the final phase of the study. Demographic characteristics were approximately similar in both groups.
Most participants in both groups had under diploma, were housewives and stage II patients, and primary care spouses (Table 1).

\begin{tabular}{|c|c|c|c|c|}
\hline \multirow{2}{*}{ Level of Education } & \multicolumn{2}{|c|}{ Intervention } & \multicolumn{2}{c|}{ Control } \\
\cline { 2 - 5 } & No. & $\mathbf{\%}$ & No. & $\mathbf{\%}$ \\
\hline Under diploma & 29 & $72 / 5$ & 22 & 55 \\
\hline Above diploma & 11 & $27 / 5$ & 18 & 45 \\
\hline \multicolumn{7}{|c|}{ Employment Status } \\
\hline Housewife & 37 & $92 / 5$ & 35 & $87 / 5$ \\
\hline Employee & 3 & $7 / 5$ & 5 & $12 / 5$ \\
\hline Stage I & 5 & $12 / 5$ & 5 & $12 / 5$ \\
\hline Stage II & 54 & 60 & 23 & $57 / 5$ \\
\hline Stage III & 11 & $27 / 5$ & 12 & 30 \\
\hline \multicolumn{7}{|c|}{ Primary Caregiver of Disease } \\
\hline Others & 7 & $17 / 5$ & 10 & 25 \\
\hline Spouse & 18 & 45 & 19 & $47 / 5$ \\
\hline Child & 15 & $37 / 5$ & 11 & $27 / 5$ \\
\hline
\end{tabular}

Table 1. Frequency Distribution of Research Subjects by Education, Occupational Status, Stage of Disease, and Primary Caregiver

\begin{tabular}{|c|c|c|c|c|c|c|c|}
\hline $\begin{array}{c}\text { Source } \\
\text { of } \\
\text { Changes }\end{array}$ & $\begin{array}{c}\text { The Sum } \\
\text { of the } \\
\text { Squares }\end{array}$ & $\begin{array}{c}\text { Degrees } \\
\text { of } \\
\text { Freedom }\end{array}$ & $\begin{array}{c}\text { Mean } \\
\text { Squares }\end{array}$ & F & p Value & $\begin{array}{c}\text { Impact } \\
\text { Size }\end{array}$ & $\begin{array}{c}\text { Test } \\
\text { Power }\end{array}$ \\
\hline Pre-Test & $1402 / 67$ & 1 & $1402 / 67$ & $23 / 90$ & $0 / 0001$ & $0 / 23$ & $0 / 99$ \\
\hline Group & $970 / 61$ & 1 & $970 / 61$ & $16 / 54$ & $0 / 0001$ & $0 / 17$ & $0 / 98$ \\
\hline Error rate & $4518 / 32$ & 77 & $58 / 54$ & & & & \\
\hline Total & 289846 & 80 & & & & & \\
\hline
\end{tabular}

Table 2. Results of Covariance Analysis of Fatigue Score of Patients with Breast Cancer after Energy Conservation Strategies Training in Intervention and Control Group by Controlling Pre-Test Effects

\begin{tabular}{|c|c|c|c|c|}
\hline \multirow{2}{*}{$\begin{array}{l}\text { Time } \\
\text { Group }\end{array}$} & $\begin{array}{c}\text { Pre- } \\
\text { Intervention }\end{array}$ & \begin{tabular}{|c|} 
Post- \\
Intervention \\
\end{tabular} & Changes & \multirow{2}{*}{$\begin{array}{l}\text { Paired- t } \\
\text { Test }\end{array}$} \\
\hline & Mean \pm SD & Mean士 SD & Mean \pm SD & \\
\hline Intervention & $66 / 60 \pm 19 / 03$ & $98 / 25 \pm 19 / 61$ & $31 / 65 \pm 23 / 12$ & $\begin{array}{c}\mathrm{t}=-8 / 65 \\
\mathrm{df}=39 \\
\mathrm{p}=0.01\end{array}$ \\
\hline Contrail & $62 / 92 \pm 19 / 65$ & $60 / 05 \pm 16 / 46$ & $-2 / 87 \pm 8 / 20$ & $\begin{array}{c}\mathrm{t}=2 / 21 \\
\mathrm{df}=39 \\
\mathrm{p}=0.03\end{array}$ \\
\hline $\begin{array}{c}\text { Independent t- } \\
\text { test }\end{array}$ & $\begin{array}{c}\mathrm{t}=0 / 84 \\
\mathrm{df}=78 \\
\mathrm{p}=0.39\end{array}$ & $\begin{array}{l}t=9 / 43 \\
f d=78 \\
p=0.01\end{array}$ & $\begin{array}{c}\mathrm{t}=8 / 90 \\
\mathrm{df}=78 \\
\mathrm{p}=0.01\end{array}$ & \\
\hline \multicolumn{5}{|c|}{$\begin{array}{c}\text { Table 3. Comparison of Mean and Standard Deviation of Caring Self- } \\
\text { Efficacy Score of Breast Cancer Patients before and after Energy } \\
\text { Conservation Strategies Training Intervention in Intervention and } \\
\text { Control Group }\end{array}$} \\
\hline
\end{tabular}

In the case of fatigue level, the mean pre and postintervention fatigue score was $55.60 \pm 14.63$ and $9.85 \pm 54.97$, respectively, which indicated a significant reduction. The results of covariance test showed that the fatigue score was significantly reduced in the intervention group compared as compared to the control group after intervention $(\mathrm{p}=0.001)$ (Table 2). The results of paired t-test regarding self-efficacy also showed that intervention of energy conservation strategies training improves caring self-efficacy in these patients (Table 3).

\section{DISCUSSION}

The aim of this study was to investigate the effect of energy conservation strategies training on fatigue and factors related to caring self-efficacy in patients with breast cancer. The results of this study showed the positive effect of energy conservation strategies training intervention on fatigue. The mean fatigue score was $9.97 \pm 54.85$ and $7.23 \pm 63.95$ out of 
100 in the intervention and control group patients after intervention, respectively. Given that higher scores indicate greater fatigue; the severity of fatigue is significant. Fatigue was reported at moderate level in the majority of patients $(75.8 \pm 54.65)$ out of 100 , (Chehregosha et al), while Tabrizi Moghaddam et al. reported the mean of the total fatigue score of $7.78 \pm 22.7$.

In a clinical trial, Yates et al used an educational intervention program to manage fatigue and the results show a significant difference between the two groups in terms of the fatigue rate and the intervention group outperform the control group in the case of fatigue management. The results of Reef's et al.'s study showed an improvement in fatigue status of the intervention group after the intervention. $(23,24)$ Chemotherapy can cause fatigue for a variety of reasons, but according to Yarbro, Frogge, Goodman, and Grone Wald (2000) chemotherapy-induced fatigue is primarily caused by tumor destruction and the accumulation of waste products resulting from cellular destruction and damage to the normal tissues of the gastrointestinal tract and bone marrow.

Since numerous factors are involved in the development of cancer-related fatigue, fatigue should be treated before it becomes a chronic and problematic complication. Depending on one's personality, mental status, and extent of disease, various methods must be employed for the treatment of fatigue.(25) A wide range of drug and cancer-related fatigue reduction non-drug methods non-drug interventions have been reviewed. Winningham (1983) for the first time suggested the positive effect of exercise in breast cancer patients undergoing chemotherapy. His research findings indicated an increase in patients' physical capacity.(26) Therefore, providing training and support for cancer patients to cope with the cancer-related fatigue seem to be a strategy to control fatigue and improves health status in these patients.(27)

Despite the efficacy of specific non-drug methods for controlling fatigue, they are less valued so that the most common methods used by patients were lying down (80.7\%) and worshiping (77.9\%) and the least frequently used method included exercise (5\%) and warm-up (21.4\%) (Safavid et al). (28) Regarding the high prevalence of lying down and stop working, stop working and resting may be the first step one take to deal with an unpleasant feeling like fatigue. Concerning the lower use of methods, such as exercise and walking, it may be argued that patients' incorrect perception that they will feel more fatigue if they use these methods has led them to use these methods less frequently; however, based on the results of many studies, appropriate exercise activities have a significant role in decreasing fatigue severity. In the present study, one of the methods taught to patients in the form of an educational package is how to perform relaxation activities. Relaxation has many positive effects such as decreasing weakness and fatigue, increasing the effect of conventional medications, increasing patient tolerance, and leading him/her to be more involved in the treatment process. (29)

In studies on the efficacy of two non-drug methods of progressive muscle relaxation and music therapy on pain in cancer patients by Shaban et al., (2006) and the effectiveness of progressive muscle relaxation by Lee and Garsin (2010) showed significant reduction in stress, sleep problems, mood disorders and fatigue symptoms of cancer patients.(30)
In the present study, the post-intervention self-efficacy level in cancer patients undergoing chemotherapy was significantly increased in the intervention group $(\mathrm{p}=0)$. In studies by Lev et al. (1996) and Akin et al. (2008), selfefficacy levels of cancer patients were $(135.55 \pm 35.26)^{(31)}$ and (96.02 \pm 28.6$)$,(32) respectively. The self-efficacy level of cancer patients undergoing bone marrow transplantation in Azizi-Fini's study (2011) and haemodialysis patients in Habibzadeh et al. (2010) was $81.02 \pm 16.53$ and $50.73 \pm 7.5$, (33) respectively. There has been no article similar to the present article investigating the effect of energy conservation strategies on the self-efficacy.

self-efficacy means having confidence in yourself and your ability to perform successfully; so, it seems obvious that people who have positive and high self-efficacy won't leave the scene in challenging situations and do not feel helpless. However, self-efficacy decreases among women with breast cancer due to a lack of physical strength, reduced ability to perform day-to-day activities, frequent and prolonged hospitalizations, and depression. Self-efficacy helps one not to lose his or her mobility and to pursue a career or activity with regard to the disease and his/her specific characteristics. ${ }^{(34)}$

Overall, it can be said that cancer is very inconvenient event for everyone, and the subsequent fatigue is an unpleasant experience for the patient. Although we can't completely prevent physical, emotional, and cognitive problems in these patients, it is possible to improve the patient's energy supply and prevent the progression or creation of new problems caused by fatigue that can also negatively affect self-care self-efficacy through counseling and training on how to deal with these problems. Therefore, healthcare providers' awareness of this fact is the most important step toward optimal patient care.

\section{CONCLUSIONS}

Intervention through energy conservation strategies resulted in reduction of fatigue and increased self-caring efficacy of patients. Educational intervention can be used as an effective strategy and a complementary therapy along with other therapies to reduce fatigue in patients with breast cancer.

\section{ACKNOWLEDGEMENT}

This article is taken from a master thesis on intensive care of Zahedan College of Nursing and Midwifery. Hereby, the authors would like to express their thanks to the Research Council of Zahedan University of Medical Sciences for registering the article. They also express their gratitude to the respected head of Ali ibn Abi-Talib and Khatam-al Anbiya Hospitals of Zahedan, dear head nurses, nurses, staffs and patients of Oncology Department of Khatam Al-Anbia Hospital and Chemotherapy Department of Ali ibn Abi-Talib Hospital who have contributed to the data collection. 


\section{REFERENCES}

[1] Isikhan V, Güner P, Kömürcü $S$, et al. The relationship between disease features and quality of life in patients with cancer-I. Cancer Nursing 2001;24(6):490-5.

[2] Omar S, Khaled H, Gaafar R, et al. Breast cancer in Egypt: a review of disease presentation and detection strategies. East Mediterr Health J 2003;9(3):448-63.

[3] Sarabadani J, Ghanbariha M, Khajehahmadi S, et al. Consistency rates of clinical and histopathologic diagnoses of oral soft tissue exophytic lesions. Journal of Dental Research, Dental Clinics, Dental Prospects 2009;3(3):86-9.

[4] Pedram M, Mohammadi M, Naziri GH, et al. Effectiveness of cognitive-behavioral group therapy on the treatment of anxiety and depression disorders and on raising hope in women with breast cancer. Journal of Woman \& Society 2011;1(4):61.

[5] Ahmed F, Mahmud S, Hatcher J, et al. Breast cancer risk factor knowledge among nurses in teaching hospitals of Karachi, Pakistan: a cross-sectional study. BMC Nursing 2006;5(1):6.

[6] Akbari M, Mozaffar M, Heidari A, et al. Recurrence and survival effect in breast conserving surgery: What are the predictive and/or prognostic factors? Iranian Journal of Cancer Prevention 2011;4(2).

[7] Khalil OA, Ahmed MR. Evaluation of early results of breast conserving therapy in treatment of breast cancer. Zagazig University Medical Journal 2015;19(1).

[8] Moncayo Á, Silveira AC. Current epidemiological trends of Chagas disease in Latin America and future challenges: epidemiology, surveillance and health policies. American Trypanosomiasis Chagas Disease, $2^{\text {nd }}$ edn. Elsevier 2017: p. 59-88.

[9] Olsen SJ. Instruments for clinical health-care research. $3^{\text {rd }}$ edn. Sudbury, Mass: Jones \& Bartlett Publishers 2004.

[10] Jones JM, Olson K, Catton P, et al. Cancer-related fatigue and associated disability in post-treatment cancer survivors. Journal of Cancer Survivorship 2016;10(1):51-61.

[11] Hilarius DL, Kloeg PH, Van Der Wall E, et al. Cancerrelated fatigue: clinical practice versus practice guidelines. Supportive Care in Cancer 2011;19(4):531-8.

[12] Moore-Higgs GJ, Almadrones LA, Gossfeld LM. Women and cancer: a gynecologic oncology nursing perspective. Jones \& Bartlett Learning 2000.

[13] Rose AG, Regina MF. Oncology nursing secrets. 2nd revised edn. London, UK: Elsevier Health Sciences 2001: p. 365-84.

[14] Tascilar M, de Jong FA, Verweij J, et al. Complementary and alternative medicine during cancer treatment: beyond innocence. The Oncologist 2006;11(7):732-41.

[15] Harris SR, Schmitz KH, Campbell KL, et al. Clinical practice guidelines for breast cancer rehabilitation: syntheses of guideline recommendations and qualitative appraisals. Cancer 2012;118(Suppl 8):2312-24.

[16] Mendoza TR, Wang XS, Cleeland CS, et al. The rapid assessment of fatigue severity in cancer patients: use of the Brief Fatigue Inventory. Cancer 1999;85(5):1186-96.
[17] Chan R. Self-management associated with fatigue in patients with advanced cancer: a prospective longitudinal study, Queensland University of Technology. 2014.

[18] Tabrizi FM, Alizadeh S, Gozali N. The effect of energy conservation strategies on cancer-related fatigue during breast cancer chemotherapy in Urmia. The J Urmia Nurs Midwifery Fac 2017;14(10):830-6.

[19] Mehri NS, Pashandi Sh, Mahmoodi H, et al. Assessment of fatigue and spirometery parameters in chemical war victims with respiratory disease. Iran J War Public Health 2010;2(4):29-35.

[20] Smets EM, Garssen B, Bonke B, et al. The Multidimensional Fatigue Inventory (MFI) psychometric qualities of an instrument to assess fatigue. J Psychosom Res 1995;39(3):315-25.

[21] Hafezi S, Zare H, Mehri SN, et al. The Multidimensional Fatigue Inventory validation and fatigue assessment in Iranian distance education students. Distance Learning and Education (ICDLE), 2010 4th International Conference on; 2010: IEEE.

[22] Fini IA, Adib-Hajbaghery M, Fard AS, et al. The effect of health-promotion strategies education on self-care selfefficacy in patients with bone marrow transplantation. 2011;4(3):109-16.

[23] Reif K, De Vries U, Petermann F, et al. A patient education program is effective in reducing cancer-related fatigue: a multi-centre randomised two-group waiting-list controlled intervention trial. European Journal of Oncology Nursing 2013;17(2):204-13.

[24] Yates P, Aranda S, Hargraves M, et al. Randomized controlled trial of an educational intervention for managing fatigue in women receiving adjuvant chemotherapy for early-stage breast cancer. Journal of Clinical Oncology 2005;23(25):6027-36.

[25] Horneber M, Fischer I, Dimeo F, et al. Cancer-related fatigue: epidemiology, pathogenesis, diagnosis and treatment. Deutsches Ärzteblatt International 2012;109(9):161-71.

[26] Winningham ML. Effects of a bicycle ergometry program on functional capacity and feelings of control in women with breast cancer. Columbus, OH: The Ohio State University, 1983.

[27] Ahlberg K, Ekman T, Gaston-Johansson F, et al. Assessment and management of cancer-related fatigue in adults. The Lancet 2003;362(9384):640-50.

[28] Faragollahi M. Strategies used by patients receiving chemotherapy to relieve fatigue. Iran Journal of Nursing 2004;17(38):58-64.

[29] León-Pizarro C, Gich I, Barthe E, et al. A randomized trial of the effect of training in relaxation and guided imagery techniques in improving psychological and quality-of-life indices for gynecologic and breast brachytherapy patients. Psycho-Oncology: Journal of the Psychological, Social and Behavioral Dimensions of Cancer 2007;16(11):971-9.

[30] Van Der Lee ML, Garssen B. Mindfulness-based cognitive therapy reduces chronic cancer-related fatigue. PsychoOncology 2012;21(3):264-72. 
[31] Lev EL, Owen SV. A measure of self-care self-efficacy. Research in Nursing \& Health 1996;19(5):421-9.

[32] Akin S, Can G, Durna Z, et al. The quality of life and selfefficacy of Turkish breast cancer patients undergoing chemotherapy. European Journal of Oncology Nursing 2008;12(5):449-56.

[33] Habibzad HM, Davarpanah M, Khalkhali H. The effect of applying Orem self-care model on the self-care self- efficacy in hemodialysis patients. J Oromieh University of Medical Sciences 1390;10(2):190-9.

[34] Woby SR, Urmston M, Watson PJ. Self-Efficacy mediates the relation between pain-related fear and outcome in chronic low back pain patients. European Journal of Pain 2007;11(7):711-8. 